\title{
Indicators and criteria for assessing ITS services in the context of road traffic safety
}

\author{
Mirosław Siergiejczyk ${ }^{1}$, and Adam Rosiński ${ }^{1, *}$ \\ ${ }^{1}$ Warsaw University of Technology, Faculty of Transport, 00-662 Warsaw, Koszykowa 75, Poland
}

\begin{abstract}
Transport telematics systems integrate information technology with telecommunications for the purposes of transport systems. This helps to improve the safety of vehicles and facilities involved in transport tasks. At the same time, the efficiency of using transport infrastructure and means of transport increases. The development and use of specialised IT applications that use data from transport telematics systems helped to create Intelligent Transport Systems (ITS). Currently, in Poland (in Europe and in the world), more and more advanced services offered by Intelligent Transport Systems are being developed and implemented. It is particularly relevant in road transport, especially because Poland's road safety is insufficient compared to other European countries. The article presents the authors' proposed indicators and criteria that can be used for assessing ITS services in the context of road safety. The authors conducted analyses to study the application of AHP (Analytic Hierarchy Process), if ITS services were to be used to improve road safety. Then, it will be possible to choose one solution from all the assessed ones.
\end{abstract}

\section{Introduction}

Transport telematics systems are systems in which IT and telecommunications solutions are integrated for the purposes of various transport modes. The use of this type of solutions results in an increase in the efficiency of using transport infrastructure and means of transport [1-3]. At the same time, it also increases the level of safety of travellers, vehicles and facilities implementing transport tasks. Specialised IT applications use data obtained from transport telematics systems. This is how Intelligent Transport Systems (ITS) were created. Currently, in transport they are among the most complex systems. Their effectiveness depends on the amount of information received from measuring devices and algorithms used in IT applications [4].

The use of ITS solutions has a positive effect on travelling conditions both in private and public road transport. The implementation of intelligent transport systems is one of the most economically efficient methods for improving traffic.

From the perspective of reliability and operations, transport telematics systems and intelligent transport systems function under varied conditions [5,6]. Observations of how they operate in the road transport environment confirm that they depend on the reliability of

\footnotetext{
* Corresponding author: adro@,wt.pw.edu.pl
} 
individual subsystems and efficient management of their operational process [7]. Therefore, an operational analysis should take into account not only the reliability of subsystems, but also the efficiency of the operational management process. It is important to ensure that scientific studies represent phenomena occurring in reality (including electromagnetic interference [8-10]) in research models of intelligent transport systems. Such an approach makes it possible to determine the relevant reliability and operating indicators which will help to assess ITS solutions when they are implemented.

The proper functioning of intelligent transport systems has a significant impact on road safety [11]. The state of inability of ITS electronic devices, as well as errors in functioning of IT applications may lead to the occurrence of states of impendency over safety $[12,13]$. The reliability theory involves analysis of the impact of damage on the system's specific reliability indicators. The areas of interest of the safety theory includes the effects of damage and errors. They may lead to the occurrence of states of impendency over safety (which is particularly important from the perspective of a transport process). Therefore, it is important to correctly determine which of the system's states can be considered acceptable or unacceptable from the perspective of safety (including partial usability states).

One way to improve road safety is to implement modern solutions of intelligent transport systems [14]. ITS systems should have specific indicators to help with comparing them with one another so that the most favourable ones are selected. As regards devices and systems, one of the most important criteria is reliability and operation. The reliability of ITS solutions is affected by the reliability of subsystems and the use of redundant structures. The first solution prevents damage, although the second one leads to the ITS system expansion, but it helps to tolerate damage (by the existence of partial usability states). When analysing ITS solutions, the quality of information that is obtained by these systems from various types of sensors is also crucial. The functioning of ITS solutions is also significantly affected by oscillations. Another relevant issue is the correct supply of devices used in ITS.

When modern intelligent transport systems are implemented, they must be compared and assessed. Therefore, there is a need to develop criteria which would include indicators that can assess ITS services in order to improve RTS (Road Traffic Safety) and traffic efficiency. Such an approach was presented by the authors in this publication.

\section{Intelligent transport systems}

One of the more important elements in the functioning of intelligent transport systems is information. It is transmitted with the use of various transmission media (wired and wireless). The use of electronic, telecommunications and IT devices results in the fact that, in reality, ITS solutions constitute complex ICT systems [15-17]. The result is that they are highly susceptible to various types of risks, including those related to the impact of electromagnetic interference.

The implementation of ITS systems has a positive impact on the transport system, among others, by:

- increasing road capacity,

- improving road safety,

- decreasing travel time and energy consumption,

- $\quad$ improving the quality of the natural environment (reduction of exhaust emissions [18]),

- making travel more comfortable and improving conditions for drivers, public transport travellers and pedestrians, 
- $\quad$ reducing road fleet management costs and those associated with road surface maintenance.

To achieve the desired outcomes, road system managers must have access to incoming data within a specified time. Some of the data must be available in real time (e.g. alarms, emergency connections, camera images) [19,20]. Other data can be transmitted with short delays (delays are permissible depending on the type of service). A part of the data is directly stored in the devices, and then passed on at specified time intervals in aggregated or pre-processed form. In order to make reasonable decisions, managers should have the possibility to verify the incoming data and have a good understanding of the situation. Therefore, visual monitoring systems are also applied. Thanks to them, they can monitor points in real time which are relevant from the perspective of Road Traffic Safety and to document the incidents and measures taken.

Intelligent transport systems consist of many subsystems. The tasks performed by individual subsystems help to implement all of the ITS functions. Thanks to that, it is possible to effectively monitor and control the traffic, predict dangerous situations, manage traffic incidents, maintain roads and implement other activities (including public safety) that are necessary for the proper operation of roads and motorways.

The objective of intelligent transport systems is to provide services for users and stakeholders. According to ISO 14813-1:2007 [21], there are 49 groups of services offered in the field of intelligent transport systems. They were divided into 12 more general domains of operation of intelligent transport systems.

The ITS services implemented in urban areas primarily include road traffic management, passenger information services, vehicle fleet management, public transport, incident management and electronic payment services. In addition to urban areas, ITS services also cover non-urban areas such as traffic management on expressways. An example of the ITS solution implemented in such areas can be, for example, sectional speed measurement (SPECS). If they want to deliver these services, contractors must have a set of appropriate tools for implementation. They must also have expertise in using these tools. A team of qualified employees is also required not only to implement a specific solutions but also to implement the services, e.g. in traffic control centres.

The rich offer of services in the ITS market helps to meet the diverse needs of road users and road managers. It is safe to say that the offer guarantees improvements to how transport systems operate, improves the safety of users of these systems and provides support to public services.

When designing the solutions used in ITS systems and selecting technology, it is important to take into account many various factors. Therefore, in order to assess individual solutions for the implementation of specific ITS services, it is necessary to develop criteria and indicators. Such an approach will help to make an assessment and then select the right solution for the specific assumptions.

\section{Issues involved in assessing ITS services}

By analysing in detail various types of ITS solutions and the technologies for implementing ITS services to improve road safety and traffic efficiency, the following indicators are proposed for the purposes of assessment:

- group of indicators characterising the services:

- probability of service accessibility,

- probability of service availability,

- probability of service continuity,

- guaranteed service quality, 
- delays in information transmission,

- group of economic indicators:

- operating cost,

- cost of starting a new service/function,

- costs/benefits in the life cycle,

- compatibility with solutions already in use.

The above indicators were proposed because they help to assess effectively ITS services and their contribution to better road safety and traffic efficiency, and at the same time, it is possible to choose the most favourable ones.

The indicators characterising the services were adopted as the first criterion. This group includes: the probability of service accessibility, the probability of service availability, the possibility of service continuity and the guaranteed service quality and delays in the information transmission. The indicators help to assess ITS services in the context of their provision level, which is very important from the point of view of the end user (driver, passenger, manager).

The next criterion is the group of economic indicators. It included four indicators: operating cost, the cost of starting a new service/function, costs/benefits in the life cycle and the compatibility with solutions already in use. As a result, ITS services can now be compared both in terms of operating costs and the implementation of other services/functions in the future, which will increase the Road Traffic Safety level. The economic indicators are very important because it will be possible to choose a specific solution, the operation of which will be more economically rational within a specified period. The indicator - costs/benefits in the life cycle is, among others, responsible for that. The indicator of service compatibility with existing solutions is also crucial. If compatibility is ensured, it will be possible to implement specific ITS solutions by using existing infrastructure with some indication of possible requirements for modernisation or replacement of the infrastructure elements in order to meet specific functions at the sufficient level.

By assuming that in terms of criteria and procedures for the selection of ITS services, in order to improve the Road Traffic Safety and traffic efficiency, the AHP (Analytic Hierarchy Process) method will be applied. The method is part of multi-criteria decisionmaking support [22], this is why the following criteria will be adopted:

- service criteria,

- economic criteria.

Figure 1 presents the structure of a decision-making model (with the use of the AHP method) within the framework of selecting ITS services in order to improve Road Traffic Safety and traffic efficiency.

The analysis of various electronic, telecommunications and IT solutions of ITS services helped to distinguish two main criteria: service and economic. Each includes specific subcriteria. Therefore, it will be possible to assess various ITS services and choose the rational one. 


\section{Objective}

\section{selection of services in order to improve the Road Traffic Safety and traffic efficiency}

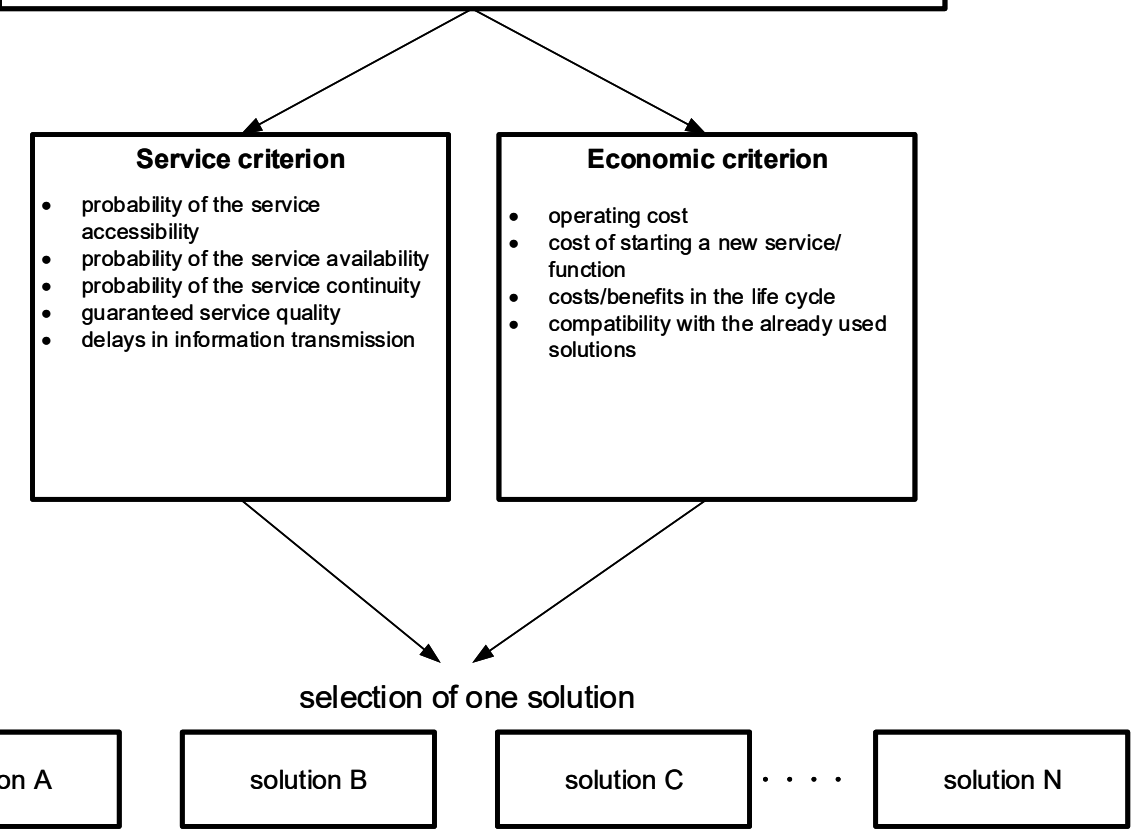

Fig. 1. The decision-making model structure (in the AHP method) within the framework of selecting ITS services in order to improve Road Traffic Safety and traffic efficiency.

The proposed indicators can also be used in other methods for supporting decision making within the framework of selecting ITS services in order to improve Road Traffic Safety and traffic efficiency.

\section{Conclusion}

The article presents the authors' proposal of indicators and criteria that can be used for assessing ITS services in the context of road traffic safety. Within the framework of the analyses, the authors offer the application of the AHP (Analytic Hierarchy Process) method for selecting ITS services in order to improve Road Traffic Safety. Then, it will be possible to choose one solution from all those assessed.

In further research, there are plans to develop an IT application that makes it possible for persons responsible for implementing ITS solutions (i.e. specific ITS services) to use the presented criteria and subcriteria for their assessment.

The article was prepared within the framework of the project RID 4D "Impact of services of Intelligent Transport Systems on the level of road safety", funded by the National Centre for Research and Development and the Directorate for National Roads and Motorways (Contract No. DZP/RID-I41/7/NCBR/2016). 


\section{References}

1. M. Siergiejczyk, K. Krzykowska, A. Rosinski, L.A. Grieco, Reliability and Viewpoints of Selected ITS System, in: 2017 25th Int. Conf. Syst. Eng., pp. 141-146 (IEEE, 2017). doi:10.1109/ICSEng.2017.68

2. B. Kalupová, I. Hlavoň, Intelligent Transport Systems in the Management of Road Transportation, Open Eng. 6 (2016). doi:10.1515/eng-2016-0062

3. L. Janušová, S. Čičmancová, Improving Safety of Transportation by Using Intelligent Transport Systems, Procedia Eng. $134 \quad$ pp. 14-22 (2016). doi:10.1016/j.proeng.2016.01.031

4. J. Młyńczak, T. Hejczyk, B. Wszołek, A. Gałuszka, D. Surma, R. Ogaza, R. Burdzik, Passenger safety and information module in intelligent integrated traffic management system, Vibroengineering PROCEDIA. 6 pp. 234-237 (2015)

5. J. Dyduch, J. Paś, A. Rosiński, The basic of the exploitation of transport electronic systems (in Polish) (Publishing House of Radom University of Technology, Radom, 2011)

6. J. Paś, Operation of electronic transportation systems (in Polish) (Publishing House University of Technology and Humanities in Radom, Radom, 2015)

7. A. Rosiński, Modelling the maintenance process of transport telematics systems (in Polish) (Publishing House Warsaw University of Technology, Warsaw, 2015)

8. J. Paś, A. Rosiński, Selected issues regarding the reliability-operational assessment of electronic transport systems with regard to electromagnetic interference, Eksploat. i Niezawodn. - Maint. Reliab. 19 pp. 375-381 (2017). doi:10.17531/ein.2017.3.8

9. M. Siergiejczyk, J. Pas, A. Rosinski, Issue of reliability-exploitation evaluation of electronic transport systems used in the railway environment with consideration of electromagnetic interference, IET Intell. Transp. Syst. 10 pp. 587-593 (2016). doi:10.1049/iet-its.2015.0183

10. M. Siergiejczyk, J. Pas, A. Rosinski, Modeling of Process of Maintenance of Transport Systems Telematics with Regard to Electromagnetic Interferences, Tools Transp. Telemat. Commun. Comput. Inf. Sci. 531 pp. 99-107 (2015). doi:10.1007/978-3-319-24577-5_10

11. U.C. Ehlers, E.O. Ryeng, E. McCormack, F. Khan, S. Ehlers, Assessing the safety effects of cooperative intelligent transport systems: A bowtie analysis approach, Accid. Anal. Prev. 99 pp. 125-141 (2017). doi:10.1016/j.aap.2016.11.014

12. A. Jodejko-Pietruczuk, S. Werbińska-Wojciechowska, Analysis of maintenance models' parameters estimation for technical systems with delay time, Eksploat. i Niezawodn. - Maint. Reliab. 16 pp. 288-294 (2014)

13. M. Siergiejczyk, K. Krzykowska, A. Rosiński, Reliability Assessment of Integrated Airport Surface Surveillance System, Proc. Tenth Int. Conf. Dependability Complex Syst. DepCoS-RELCOMEX. Adv. Intell. Syst. Comput. 365 pp. 435-443 (2015). doi:10.1007/978-3-319-19216-1_41

14. A. Parallos, U. Hernandez-Jayo, E. Onieva, I. Garcia Zuazola, Intelligent Transport Systems: Technologies and Applications (Wiley, 2015)

15. M. Rychlicki, Z. Kasprzyk, Increasing Performance of SMS Based Information Systems, Proc. Ninth Int. Conf. Dependability Complex Syst. DepCoS-RELCOMEX. Adv. Intell. Syst. Comput. 286 pp. 373-382 (2014). doi:10.1007/978-3-319-07013$1 \_36$ 
16. M. Stawowy, Z. Kasprzyk, Identifying and Simulation of Status of an ICT System Using Rough Sets, Proc. 8th Int. Conf. Dependability Complex Syst. DepCoSRELCOMEX. 224 pp. 477-484 (2015). doi:10.1007/978-3-319-19216-1_45

17. F. Losurdo, I. Dileo, M. Siergiejczyk, K. Krzykowska, M. Krzykowski, Innovation in the ICT Infrastructure as a Key Factor in Enhancing Road Safety: A Multi-sectoral Approach, in: 2017 25th Int. Conf. Syst. Eng., pp. 157-162 (IEEE, 2017). doi:10.1109/ICSEng.2017.69

18. Z. Kasprzyk, M. Siergiejczyk, Some Problems of Functional Analysis of Electronic Toll Collection System (ViaToll), Act. Transp. Telemat. Commun. Comput. Inf. Sci. 395 pp. 426-432 (2013). doi:10.1007/978-3-642-41647-7_52

19. K. Lewczuk, J. Żak, D. Pyza, I. Jacyna-Gołda, Vehicle routing in an urban area: environmental and technological determinants, WIT Trans. Built Environ. 130 pp. 373-384 (2013). doi:10.2495/UT130291

20. P. Łubkowski, D. Laskowski, Selected Issues of Reliable Identification of Object in Transport Systems Using Video Monitoring Services, Telemat. - Support Transp. Commun. Comput. Inf. Sci. 471 pp. 59-68 (2014). doi:10.1007/978-3-662-45317-9_7

21. B. Chojnacki, M. Kowalewski, A. Pękalski, Importance of national ITS architecture, (in Polish), Pr. Nauk. Politech. Warsz. - Transp. 95 pp. 29-41 (2013)

22. D. Kaszubowski, J. Oskarbski, Simulation of the process of selecting the method for detection of traffic incidents (in Polish), Logistyka. 3 (2012) 